\title{
Perceptions Of Government Stakeholders On Ageing And Assisted Care In The Cape Coast Municipal Area
}

\author{
Irene Korkoi Aboh \\ School of Nursing and Midwifery \\ College of Health and Allied Health Sciences, University of Cape Coast, Ghana. \\ Busisiwe Purity Ncama \\ University of KwaZulu-Natal, School of Nursing and \\ Public Health, Howard College, Campus, Durban, South Africa
}

\begin{abstract}
Aim: To explore the perceptions of government stakeholders on assisted care for the aged in a Metropolis, in Ghana.

Method: This is a qualitative sub-study of a larger study on developing a model for the care of the aged in the Cape Coast Metropolitan area. The following questions were put to the key informants: Have you noticed an increase in the number of the aged in the communities? What are government plans for the aged? How is the welfare and the caring from traditional attention, what is your view on the introduction of assisted care in Ghana? Data was collected through key-informant in-depth interviews with 10 government stakeholders directly in charge of policy implementation in the metropolis. Data collection took place over a period of four months from October 2016 to January 2107. The interviews were digitally recorded and transcribed verbatim, coded and analyzed.

Findings: There was no preparations made for ageing, government had plans and strategies for the aged care. Traditional caring provision is inadequate and the concept of assisted living is regarded with mixed feelings. Some informant described assisted caring as an unaccepted practice that should not be encouraged.

Conclusion: Those implementing the policies are not certain of the feasibility of the programme. Awareness of assisted living should be promoted so that the community can make their own decisions.
\end{abstract}

Keywords: aged, assisted living, government stakeholders, policy.

INTRODUCTION

Population around the world are rapidly ageing, with some of the fastest change occurring in lowand middle-income countries. Promoting healthy ageing and building systems to meet the needs of older adults are important priorities [1]. An understanding of demographic trends can help government to target policies for the future and save money for the education, retirement, taxes, healthcare, distribution of natural resources and more. More importantly, targeted policies can ease resentment emerging over demographic imbalances and exploding population- trends which are occurring in less developed regions due to decreasing fertility, ageing and longevity, resulting in ill- 
Aboh, I. K. \& Ncama, B. P. (2020). Perceptions of Government Stakeholders On Ageing And Assisted Care In The Cape Coast Municipal Area. Advances_in Social Sciences Research Journal, 7(4) 71-86.

conceived policies, unsustainable programs and squandered resources [2]. [2] added that population ageing and longevity are of significance for policymakers in both developed and less developed countries. The number of young workers is declining relative to those in the retirement category, and the growing numbers, mostly women, are surviving to advanced ages.

The different types of economic support system cover four sources of finance for consumption: labor income, net public transfers, net private transfers, and asset-based reallocations. Labor income includes employment earnings and self-employment income. Public transfers are the cash and in-kind transfer received from government in the form of healthcare, public safety and national defense, and cash transfers areas pensions and other cash allowances for older people, net of taxes and social contributions paid to the government [3]. Private transfers include both inter-household transfer and intra-household transfer. Asset-based reallocations are basically net asset income and dis-savings. Another means of financing old-age consumption is public transfer in the form of pension and healthcare, which is provided through formal government program. In developed countries, these transfers and net of taxes paid are the major source of income security after retirement. Indeed, in about half of developed countries, net public transfers cover more than $50 \%$ of older persons' consumption. [3] adds that less developed countries which have much lower levels of economic development and poor access to adequate health care will be hard pressed to meet the challenges of more elderly people, especially as traditional family support system for the elderly are breaking down. [3] suggested that policymakers in the developing world need to invest urgently in formal system of old-age support to be able to meet these challenges in the future.

\section{BACKGROUND}

The Madrid International Plan of Action on Ageing (MIPAA), adopted during the Second World Assembly on Ageing in April 2002, recognized population ageing. The shift towards a larger proportion of older people in the population is an important global trend. MIPAA linked question of ageing to other frameworks of social and economic development and human rights, calling for ensuring the wellbeing of older persons in an inclusive society for all ages.

It is suggested that as the world population continues to age, ageing-related concerns should be incorporated into the post-2015 United Nations development agenda and sustainable development goals. The document discussed current and future trends in population ageing, and their implication for social and economic development [4]. MIPAA discussions covered acceleration of global ageing in the coming decade, the projected growth of the older population which is to take place in the global South, the various sources of financial support such as labor income, asset, their families and the public program of the aged and the adaptation of the health care systems to meet the changing needs of an ageing population [4] Peoples' experiences of old age vary enormously depending on where they live. Countries that support human development throughout life are more likely to see higher levels of quality of life among older people and see them participate more in work and community. The evidence available in the Global Age Watch Index not only seeks to identify contexts in which older people fare better, but points to policy interventions that reduce their vulnerabilities [5]. The index also suggests that social and economic policies supporting older people's employment, income, health and autonomy are important for wellbeing. The best performing countries have long-standing universal pensions and better access to healthcare, as well as action plans on ageing. This approach is apparent not in some Western countries but also in middle-income 
countries like Chile, Argentina and Mauritius. To close the gap, some countries have introduced taxfinanced social pensions so that everyone can look forward to income security in old age [5].

Almost 20\% of Americans aged over 65 are in the labor force, and nearly half of all Germans in their early 60s' are also employed today, partly due to policy. Debt-laden government in Europe have cut back their pensions promises and raised the retirement age. Half a dozen European countries, including Italy, Spain and the Netherlands, have also linked the statutory retirement age to life expectancy. The shift in retirement age was strongest in the wake of the 2008 financial crisis, which hit the savings of many near-retirees. Moving away from the corporate pension plans that provided a fraction of recipient's final salary in perpetuity has also kept some people working longer [6]. More broadly, an ageing population will require increased support of various types, including income security and greater access to health care. While families have traditionally provided such support in many developing countries, increasingly this support is less reliable-particularly when women enter the workforce in larger numbers. Lower birth rates, the tendency of children to move away from their parents in widespread rural to urban migration, and new cultural norms regarding filial obligations are increasingly leaving the elderly grieving of the security they once had [7].

\section{FORMS OF SOCIAL SECURITY}

Social security is ideally the configuration of traditional, informal and formalized modern forms of action to encompass the sum of all regulations within the society aimed at guaranteeing, for an individual or a group, not only physical survival, but also general protection against unexpected risks. A situation which would entail the deterioration of their situation, the consequences which cannot be borne by the individual or a group without external assistance [8]. A large segment of African population does not enjoy social security and remain at the mercy of nature and human forces beyond their control. [8] adds that African economic are agrarian, with most of their populations deriving an income as self-employed small-scale entrepreneurs. The small size of their plots and the whims of the weather as well as an array of other contingencies make them very vulnerable to economic shocks. Since most social security arrangement caters only for the formal economy, this means that, in terms of coverage, the overwhelming majority of Africans remain unprotected by the formal means against the main risks [8]. Traditionally, the collective solidarity of the extended family, clan and the ethnic group have been the backbone of income and social security [9].

\section{Social Protection}

Families provide most support for the aged who require help. Societies develop and the practice of co-residency among several generations has begun to decline. There are increasing calls on developed mechanisms that can provide social protection for older people who are unable to earn a living and are alone and vulnerable. In developing countries, aged who needs assistance tend to rely on family support, informal services transfers, and personal savings [10]. Social insurance program are minimal and, in some cases, redistributed income to elite segment of the population who are less in need. In south Africa and Namibia, a national old age pension scheme has been instituted, these benefits are a major source of income for the entire family, as well as for the older adults [10]. The document in addition detailed that a policy framework was formulated for action on three basic pillars, health and independence, productivity and protection to enable older people to continue to make a productive contribution to society. When policies and program address the health, social, financial, and physical security needs and rights of older people, they are ensued of 
Aboh, I. K. \& Ncama, B. P. (2020). Perceptions of Government Stakeholders On Ageing And Assisted Care In The Cape Coast Municipal Area. Advances_in Social Sciences Research Journal, 7(4) 71-86.

protection, dignity and care if they are no longer able to support and protect themselves. Families are supported in their efforts to care for these older loved ones.

\section{Social Health Insurance}

The WHO has been involved in technical advisory work in assessing the social health insurance (SHI) in Kenya, Lesotho and Swaziland in collaboration with national experts from those countries. In each country, analysis of the financial, organizational and political feasibility showed that there should be workable policies for the countries in formulating general guidance [11]. The Abuja Declaration called for Africa heads of states to allocate at least $15 \%$ of annual government budgets to the health sector. In addition, if existing international commitments are fulfilled it is expected that this financial support would indeed increase substantially over time. The programme is to boost the health system by improving quality of health care and shifting away from out-of-pocket payment to prepayment of health care, or the 'cash and carry system'. The appeal to cover larger parts of the population on social health insurance has been growing, and countries including Ghana, Nigeria, and Rwanda have passed SHI laws [11].

\section{State-based system}

State-based social security systems are modelled on European experience and cater for people in the modern sector of the economic (i.e. only for those in organized public and private employment), for example, social insurance pension schemes and provident funds typically cover only $5-10 \%$ of the total labor force plus their dependents [8].

\section{Market-based systems}

Complementary market-based social security schemes run by the private insurance companies on a commercial basis have emerged alongside state-based system, even though they still play a marginal role in the total provision of social security. While the efficiency and quality of commercial social insurance system are recognized, their inaccessibility for the low-income strata renders them suitable instrument mainly for the affluent, urban-based parts of the population. Meanwhile, government still control the social security in Africa [8].

\section{Kinship-based system}

finally, the support system of the extended family is still alive in Africa, although under increasing pressure. First, the productive resources an average household commands are diminishing, mainly due to the sub-division of land from one generation to another. Second household expenditure are soaring with respect to education, health and other services [8].

\section{Aged facilities}

Demand for the home-based care is rapidly increasing as baby boomers are aging and advanced medical technologies are extending the life expectancy of disabled and chronic patients [12]. The document further estimated that by 2050, 27 million people will need some type of long-term care. The National Home Health Aide Survey (NHHAS) also estimated that almost 1.46 million older people were receiving care and were discharged in 2000 [14]. The authors add that over 14000 agencies are in the business of recruiting and training caregivers for serving patients. Home healthcare and aid workers provide over $70 \%$ of paid long-term medical care and personal assistance. Nonetheless, it is individual effort that contributes to most of the cost for care; family, friends, and other volunteers cover $57 \%$ (36\% by informal care and $21 \%$ by out-of-pocket 
payments) of long-term care responsibilities for the elderly [14]. Medical insurance picks up 38\% of total costs, followed by private insurance (3\%) and other (2\%). Medical insurance covers the bulk of total home healthcare service payments: about 37\%, per the National Association for Home Care and Hospice, and home healthcare accounted for 20.2\% of Medical insurance spending in 2006 and 2004 respectively [15].

Assisted living, overall, has thrived rapidly-understood as a general term for any residential setting not licensed as a nursing home but providing or arranging personal care routine in a homelike residential setting [16]. In nursing practice, assisted living is regulated according to the state or region, which also reflects different philosophies about who should be served in these residential long-term care settings and the relationship envisaged between assisted living and nursing homes [17]. These facilities, also referred in California as residential Care Facilities, are living arrangements that provide personal care and health services for people who may need assistance with activities of daily living (ADLs), but wish to live independently. The level of care provided is not as extensive as that which may be provided in nursing homes [18]. Assisted living is not an alternative to a nursing home, but an intermediate level of long-term care. One community may look like a modern home high-rise apartment building. Another might look like a quiet suburban town home community. Still another may resemble a resort or a country club, but there are some generalizations [19].

The homelike nature of the setting also varies a great deal among and within states, with some assisted living settings providing single-occupancy apartments and others providing accommodations in board-and-care settings with two more persons per a room [20]. Apartmentstyle assisted living, by design, offers privacy and the opportunity for autonomy. It also exposes residents to risk of everyday life associated with cooking and bathing and tends to afford staff, less opportunity for protective surveillance. Whether the service is provided with internal staff, outside home and agencies, or combination of these, assisted living tends to be more lightly staffed than nursing homes. The state calibration of valuation and quality standards does not apply to assisted living, and states are free to develop their own regulations [20]. It also combines independent environment and life style with access to onsite health care and support as needed, as opposed to 24-hour medical care provided in a nursing home [19].

\section{Design and setting}

\section{MATERIALS AND METHODS}

This is a sub-study of a larger study aimed at developing a model for the care for the aged in a Metropolis that is one of the 230 administrative Metropolis/districts in Ghana. Data was collected through individual in-depth interviews from October 2016 to January 2017. Participants were recruited from ten of the 26 sub-districts of the Metropolis.

\section{Participants and sampling}

Participants were purposively sampled and recruitment for the study were 10 government stakeholders out of 20 proposed sample. Two medical directors and one social work director, two chiefs and five political assembly members were selected as key informants. These stakeholders were heterogeneously selected based on their work affiliations and implementation of policies using the public offices they hold. Their selection criteria were based on their availability at the time of data collection. 
Aboh, I. K. \& Ncama, B. P. (2020). Perceptions of Government Stakeholders On Ageing And Assisted Care In The Cape Coast Municipal Area. Advances_in Social Sciences Research Journal, 7(4) 71-86.

\section{Data collection and techniques}

The principal investigator (first author) collected all data. A semi-structure guide was used to conduct interviews. The focus of the interview questions for this category of informants were on how the people in their communities prepared for ageing, what government plans were in place for the aged and what their views were on the provision of assisted living to the aged in their communities.

\section{Key-informant interviews}

Interviews were conducted for all these important political figures who served as a key informant for their respective communities and work environment. The interviews were meant to establish how the people planned and prepared for their retirement and ageing, and what their input would be if it was possible to begin implementing assisted living in Ghana. These questions were relevant because commencement of the programme in the communities will depend on their input and how they respect it.

Telephone appointment were booked with participant and individual in-depth interview appointments were scheduled. Individual in-depth interviews were held with all stakeholders; those who were unable to honor their invitations due to work overload were rebooked for their interaction. This was considered appropriate and effective strategy to gain understanding of the multifaceted and delicate issues on preparation for ageing. The purpose was also to allow these informants who are policy makers/implementers reflect and express their opinions in the cultural and local language and share their views on how they felt the aged should be handled, considering the existing traditional mode of caring in the community.

Table I Characteristics of participants

\begin{tabular}{|c|c|c|c|c|c|c|}
\hline Site & $\begin{array}{l}\text { Classification of } \\
\text { sub-districts }\end{array}$ & $\begin{array}{c}\text { No. of } \\
\text { participants }\end{array}$ & Sex & $\begin{array}{c}\text { Level of } \\
\text { education }\end{array}$ & Designation & Code \\
\hline \multirow[b]{2}{*}{1} & \multirow{5}{*}{ Urban } & \multirow[b]{2}{*}{2} & Male & \multirow[b]{2}{*}{ Tertiary } & Medical Director & MDO \\
\hline & & & Female & & $\begin{array}{l}\text { Assembly } \\
\text { member }\end{array}$ & AMO \\
\hline 2 & & 1 & Male & Makarata & Islamic Chief & ACA \\
\hline 3 & & 1 & Male & Tertiary & $\begin{array}{l}\text { Assembly } \\
\text { member }\end{array}$ & AMP \\
\hline 4 & & 1 & Male & Secondary & $\begin{array}{l}\text { Assembly } \\
\text { member }\end{array}$ & AMT \\
\hline 5 & & 1 & Male & Primary & $\begin{array}{l}\text { Assembly } \\
\text { member }\end{array}$ & AMA \\
\hline 6 & Perı-Urban & 1 & Female & Tertiary & $\begin{array}{l}\text { Regional social } \\
\text { worker }\end{array}$ & RSW \\
\hline 7 & & 2 & Male & $\begin{array}{c}\text { Tertiary } \\
\text { Secondary }\end{array}$ & $\begin{array}{l}\text { Medical Director } \\
\text { Clan Chief }\end{array}$ & $\begin{array}{l}\text { MDD } \\
\text { CDD }\end{array}$ \\
\hline 8 & Rural & - & - & - & - & \\
\hline 9 & & - & - & - & - & \\
\hline 10 & & 1 & Male & Secondary & $\begin{array}{c}\text { Assembly } \\
\text { member }\end{array}$ & AMK \\
\hline
\end{tabular}


The 10 face to face individual in-depth interviews each lasted between 20 and 40 minutes. Using key prompts, discussions examined the preparedness of target population for their ageing, key elements prompting traditional care in the home, and whether substitute care was necessary to enhance caring sustainability. At the start of each interview, participants were given the consent form to read and sign. Some asked for explanation of assisted living and the SWOT (Strengths Weaknesses Opportunities Threats) Analysis approach was used to provide an understanding into the Pros \& Cons of the programme. With the aim of finding out how assisted living could be remodeled to improve the lives of the aged in the specified geographical locations. Specific target individuals included two medical directors (MD) (sites 1 and 7), one regional social welfare director (RSW) (site 6), two chiefs (C) (site 2 and 7) and five politically affiliated stakeholders, unknown as Assembly Members (AM) (site 1, 3, 4, 5 and 10). Participant listened attentively as the programme was described to them and their roles if they agreed to participate.

\section{Data management and analysis}

The tape-recorded interviews were transcribed verbatim from the local language into English by the Principal investigator (PI) and a research assistant. The transcripts were checked for accuracy and quality, and cleaned for anonymity by the PI. When no discrepancies were identified, the files were coded and analyzed interpretive descriptive analysis was used to generate context-relevant knowledge for insight into how preparation for ageing was done and whether assisted care was an option to consider for these communities (Hunt, 2009). Content of the data files was initially read to identify the major thematic areas. The main task was to display data in a way that showed meaningful conceptual distinctions and provided content relating to the concept under study. Three key steps in interpretive descriptive analysis were used: detection (which involved identification), assigning the substantive content and displaying the dimensions of preparedness towards ageing. These dimensions emerged three major themes: preparation for ageing; government plans for the aged; and assisted living as a major caring option for the aged.

\section{RESULTS}

Participants showed their concern for the aged in their communities but expressed a preference for allowing the aged to stay with their relatives, on the grounds that government had no money to take over someone else responsibility. They explained how generally people prepare for old age in Ghana. They all agreed that there were substantial number of aged, as shown in two of the response;

\section{I have noticed that there are more aged in recent times, I look after 13 communities and the aged are plenty. (AMK, site 10)}

Oh!! We have the aged in our community, most of them are in the age range from 80 or 90 downwards, I meet them a lot, I meet them a lot, I am even going to meet some of them right after my talking to you. (AMA, site 5)

\section{Preparedness}

When participants were asked how members of their community prepared for ageing, they all said that the only people able to prepare financially were those in the government employment sector who had mandatory entitlement to a compulsory social security scheme. Participants were quick to respond that there was no preparation whatsoever from the informal section of the population. The following comments were offered by respondents in senior position: 
Aboh, I. K. \& Ncama, B. P. (2020). Perceptions of Government Stakeholders On Ageing And Assisted Care In The Cape Coast Municipal Area. Advances_in Social Sciences Research Journal, 7(4) 71-86.

What I have seen that people do is not prepared toward their ageing, because the people I come across are not prepared. You realize that because of the cases they present. If they had prepared, they would not be facing such problems. People from the formal sector are better than those in the informal sector. Those from the informal sector do not prepare at all. Those in the formal sector at least know they will go for pension so they have something (pension) to rely no (RSW, site 6).

Erhheii! That is one thing people do not do, all people know is their pension, it is for those who are fortunate to be in government institutions. They are covered with the social security (MDD, site 7).

I don't think we do any serious preparation consciously; we just blow with the wind... I don't think our community members make any active preparation towards their ageing. It is the family members and children who takes care of the aged ... we do not have a geriatrics base centre in Ghana ... we don't ... it is solely the responsibility of family members or children or grandchildren (MDO, site 1).

The remaining participants could not envisage or comprehend what the PI was trying to convey as preparedness for ageing and retirement.

\section{Government plans}

To assess their knowledge or awareness of a government plan for the aged, participants were asked again if they were happy with what was happening in caring services at home for the aged. Since RSW was working in close contact with the aged and the vulnerable, in monitoring and supervision of her subordinates, she had encountered many of the programmes and was in a position to offer the following comments:

You know what ...we, social workers (SWs) have these LEAP program which supports the aged who are 65+years ... it is a social grant support where we give to the aged. It is our criteria to look after people from 65+ without any support, orphans and the severe disabled. It is a programme government of Ghana has put in place for the vulnerable....Right now, the government has introduced something else called "EBAN about 2 years ago ...EBAN-it is used to cater for the aged ... when they have this card, something like discount card when they go to the hospitals... they are seen first ... they do not have to queue to be seen by the doctor... they show it that they have registered with the government of Ghana and services will be provided. When they are going to take government transport, they will be given 50\% discount-so right now it is for the government owned transport ... they seem to be obeying these laws. ... But for the privately-owned transport... I don't think are adhering to this ... in that document (policy) they talked about training geriatric doctors... but they have not been able to implement it...but the EBAN has started and it is on pilot basis, (RSW, site7).

Using the prompts to get the informants to think about government policy for the aged, only RSW could give an account of all the program for the aged (NHIS, LEAP and EBAN). The other two medical directors had knowledge about NHIS but not the other program; the five assembly members knew about NHIS and LEAP but not EBAN. Those who knew about LEAP got to know about it when were 
elected to office, otherwise they would not have known whether or when the pilot project fell into jurisdiction. Those who are managing the LEAP decides who benefits and who does not. The beneficiaries are sometimes not aware of this factor until they are approached by the assembly member. Respondents' comments reflected some of the difficulties:

The LEAP is not regular ... even my area is not part of it ... I have now sent some peoples' names... I had to use my own discretion to kick some people out. If they are many ... accepting my list will be very difficult with an intention that $65+$ are frailer than 60 years. (AMK, site 10) normally the LEAP is for those who come from poor backgrounds ... from 90 years down ... even if you are 60 years and from a poor background. It will depend on me if I should include you or not (AMA, site 5).

Another assembly member reported that the LEAP had existed 12 years previously. He had read about it but it had been politicized and had lost its value, making it less popular:

Really... I read about it. It was introduced 12 years ago ... now, it has been politicized so the kind of beneficiaries who are to get it are not getting it. They are to come to the communities, see the chiefs, opinion leaders and unit committee members to identify who really needs it but they do not. Somebody might be an aged but not needy. For the fact that he/she belongs to a certain political party or because an opinion leader is in government, he/she will add this person's name who might not be a needy aged. The LEAP is not working like it should (AMP, site 3).

\section{Assisted living \\ Perception of assisted living}

Despite the explanation given to participants on assisted living as offering a home-like atmosphere, participants in higher offices were adamant that there should not be any idea of shifting of responsibility. Grasping the various implications of assisted living remained problematic for them. The following comments indicate concerns expressed by the three directors:

Oh ... I see ... Health Aid Ghana had a sort of care like that for the aged in Accra. But it was like a day care. They (aged) go in the morning and come back home in the evening but for some time now it has gone cold .... it used to be very active. Do you think Ghana can do that? In Ghana, we are not ready for the care you are mentioning ... it will be for the rich ones, only for people who are rich ... but only few can patronize such a programme. Usually, for these people they like people to take care of their parents ... but how many are these people can afford to pay for their parents? (RSW, site 6).

It will not be possible, nationally it would be a challenge because of funds (MDD, site 7) and the third director, 'does our culture allow us to put our parents somewhere? At the moment things do not look too good but No.... Imagine me being alive and I put my parents in a home then be visiting them ... while I am working somewhere ... it is not part of our culture. (MDC, site 1)

The assembly members felt the programme was a good idea because some of the aged were living in deplorable conditions even in the presence of family members. Others confused assisted care 
Aboh, I. K. \& Ncama, B. P. (2020). Perceptions of Government Stakeholders On Ageing And Assisted Care In The Cape Coast Municipal Area. Advances_in Social Sciences Research Journal, 7(4) 71-86.

with hospital care and suggested that skilled attendants be deployed to visit the aged in their own home environments:

It is a laudable idea and it is good .... I agree with this idea ... some have the money ... they do not have a problem but those who do not have ... is the problem (AMP, site 3).

For the hospital care, a clinic has purposely been opened for the aged in town ... and they see to only the aged on OPD basis ...the people know about the arrangement and they have doctors and nurses ... it is under the health services. I think government can assist by sending these doctors and nurses to the community to care for the aged.

(AMK, site 10)

It will be good if we can have an aged home ... I heard of one recently in Accra and it was on a day care style... I heard of it on the radio where you can send your mom or dad and you can come for them when you get back from work ... if that home will have a nurse or a stand-by doctor that will be fine (AMP, site 3).

But after a brief silence and deeper consideration (when the PI thought the interaction was over) respondents saw the usefulness of the programme and commented that it was likely that Ghana would one day rise to this kind of care:

People come here to ask for caregivers to take care of their parents. I understand what you are driving at; there are people who can afford what you are trying to do but how many are they? Only few can afford to live the services to their mothers to someone else. ... I am categorically saying mothers because for the men ... you scarcely see them living alone (RSW, site 6).

I am sure as time goes on and as society changes... we will come to accept that very soon, we will embrace it ... even looking for a maid for your household is not easy.... Everyone wants his or her child to go to school so the traditional caring is gradually disappearing. (MDO, site 1)

If there would be a policy for a special insurances service in our active employment phase or tenure of employment ... I mean a special insurance for this project for monthly contributions ... once the money is kept for us .... we can enrol into the programme ... and by then a structure will be put in place. (MDD, site 7).

\section{Funding}

Funding is crucial for assisted living; it assures protection of customers, determines whether care can be provided either directly or indirectly affects maintenance of infrastructure and the immediate environment, which are factors that can be costed. When participants were asked how they felt the programme should be funded, one said it was a programme for the rich so they would be able to handle it without any problem since they can afford to keep their family members in hospital just to have time to celebrate afakye (festivals): 
The family must take up payment of the bills ... Yea - people will be ready and willing to pay.... Someone was telling that when it is "afakye" people intentionally put their aged parents in hospitals so that no one will come and see them ... and I was surprised (RSW, site 6).

Others felt the money could be put into government chest so that government could support the programme and from which it would be disbursed by the assembly members;

Hmmm (sigh) I think-it is a good idea. We should factor it into the Metropolitan Assembly's funds so that government can support. Government must play a role, because if we do not budget, government cannot support. ... Government must take a percentage then family members also take up rest (AMK, site 10; AMT, site 4).

Another participant felt it should be handled like the social security system so individuals contribute to their own aged care:

If there could be a policy that people, during their active employment or tenure of work could make special monthly contributions like the social security system ... once the money is there, they can go into the programme (MDD, site 7).

\section{Strategy}

Planning and gathering resources for the effectiveness of the programme is very important. When participants were asked what strategies are to be put in place, there was consensus that intensive sensitization and education was needed for the existing policy on care for the aged. Three participants agreed to the sensitization and education was needed on the existing policy, another thought the best option was to let the aged stay in their own homes with the provision of care by government by means of hot meals rather than moving them elsewhere; four participants felt the day- care approach was the best because it provides mental stimulation.

Others suggested that personnel should first be trained so that they would lobby for the programme, and that the elderly should remain at home for continuation of traditional care to maintain their self-esteem. Three participants had nothing to say, since everything depended on policy implementers. The following comments give an indication of the range of responses:

I think we need to do a lot of sensitization and education for them to understand the need to care for their parents and on aged policy in Ghana ... It was drafted in 2003 and passed into an act but up till now nothing has been done about it (RSW, site 6).

It is a big programme, if the government can think about this issue it will be a good thing. You know every community and its challenge. So, I think for me we need to look at the programme again so that the aged stay in their homes and we focus on their health. Then we add the style of the school feeding programme where we can serve hot meals (AMT, site 4). 
Aboh, I. K. \& Ncama, B. P. (2020). Perceptions of Government Stakeholders On Ageing And Assisted Care In The Cape Coast Municipal Area. Advances_in Social Sciences Research Journal, 7(4) 71-86.

I think we can do a day-care where they will be brought to the shed or shelter.

(AMP, site 3; $A M A$, site 5; AMK, site 10; AMO, site 1)

We should train personnel, both nurses and doctor ... it is a whole complex thing ... and it has to begin from somewhere. After training the workforce then they lobby for the rest. You see we live in an environment where planning is done in isolation to reality ( $M D D$, site 7 ; $A M K$, site 10$)$.

We should train nurses because geriatric nursing is not common in the country. But sending them to an institution is not the best ... they will be thinking we are cutting them from their grandchildren and all that. They will not be happy to be cut off from society ... no connections and all that, it will lower their self-esteem ... in our society we do not do that (MDD, site 7).

\section{DISCUSSION}

In our investigation of government stakeholders' perceptions of assisted living as a new option in caring for the aged, it has become apparent that those responsible for implementing government policies in the metropolis were poorly informed about the potential existing policies to improve people's lives in the communities. Three major themes emerged from the analysis: preparedness', government plans, and assisted care. Preparedness in relation to the way people prepare for retirement and old age, and government plans could help people plan properly for their ageing. Informing participants about assisted living gave them insight about the function and practiced of the programme elsewhere.

Findings suggested that people did not prepare for their ageing, particularly with those working in the informal sector. As two stakeholders put it, people just flowed with the tide. [21] reported that in retirement planning, which makes them prime candidates for poverty. It has also been documented that in traditional gender roles work and retirement are firmly in the male domain, women considered only in relation to their husbands' retirement. Despite women's increasing presence in the workforce since World War II, research into women's retirement, including their preparatory behaviors, shows that women, in general, did less retirement planning than men [22]. In Ghana, men and women alike failed to plan for retirement and old age. This could be because they lack resources to live on, let alone save - all available income needing to be spent on essentials such as school fees, utilities, etc. In the formal sector, workers not entitled to employment benefits and not understanding the social security system felt that they could take something home but ended up with nothing. This is clear from research finding that workers expect to rely on employerprovided benefits that they are unlikely to receive in terms of their ultimate pension plan entitlements as retirees [23].

Participants in higher offices were able to identify some elements of the government plan for the elderly, possibly because they had been working with the policies. Aside from this, there was general ignorance among the stakeholders in relation to pertinent aspects of the policies. As noted by [24], this has been highlighted in financial planning reports which continue to have high priority for both private and public policy makers. The authors point out that numerous policy efforts and marketing strategies have been undertaken to capture public attention, which is important for encouraging savings and planning for post-working life. They note in this regard the increasing 
prominence of advertising from financial service and counselling firms in creating public awareness about the importance of planning for better financial protection.

[1] notes that the goal of active ageing calls for action in a variety of sectors, including health, social services, education, employment and labor, finance, social security, housing, transportation, justice and rural and urban development. All policies need to support intergenerational solidarity and include specific targets to reduce inequities between women and men and among different subgroup within the older population. Particular attention needs to be paid to older people who are poor and marginalized, and those who live in rural areas.

This has been done by Ghana but its implementation is a problem. Beneficiaries are not aware of this option from government and what is given to them. Assembly Members might also decide which beneficiary does or does not belong to the scheme if this aged is a member of his political group or party.

Older people's living arrangements reflect their need for family, community, or institutional support. Living arrangements also indicate sociocultural preferences. Some choose to live in nuclear households while others prefer extended families. The number, and often the percentage, of older parents living alone is rising in most countries. Even in societies with strong traditions of older parents living with children, such as in Japan, traditions of older parents living arrangements are becoming less common [25]. This is in line with reports from participants when they affirmed that even in the presence of relatives aged are neglected. When asked what their perceptions were of assisted care, participants were adamant that it was time the traditional caring system was upgrading or remodeled. Long- term care for older people has become a key issue in the West and in many less developed middle-income nations. Such care involves a range of support mechanism such as home nursing, community care and assisted living, residential care, and long- stay hospitals. Whiles the cost of long-term care is a burden to families and society, there are other concerns as well [25] which could be affection from family members, society or of the church [26]. Some participants were concerned about separation or alienation of the aged from their families and opted for a day-care model instead of moving old people into a home. Others wished to see provision of hot meals at home so that those being cared for could be given improved nutrition without having to leave their homes. Funding, they all agreed, should be handled by the family and relatives of the aged.

There was strong approval for designing a properly organized strategy for the programme that would include infrastructure and guidelines. In the discussion of sensitizing and educating people on how to care for the aged participants suggested that this could take the form of training in assisted caring for semi-skilled caregivers at community level. Some suggested that it was important for the programme to offer a comfortable and appealing environment that would attract consumers and encourage them stay. Participant in higher offices and directly in charge of policy implementation suggested that best way to lunch this programme was to formulate a policy then train personnel, otherwise it would not work - a traditionally bureaucratic approach to issues which seldom produces quick results. 
Aboh, I. K. \& Ncama, B. P. (2020). Perceptions of Government Stakeholders On Ageing And Assisted Care In The Cape Coast Municipal Area.

\title{
CONCLUSION
}

The aim of this study was to investigate whether traditional care for the aged could be remodeled into a culturally and morally accepted caring system. The idea was approached through SWOT analysis. Stakeholders were government representative with busy schedules it was often difficult to get hold of them for the individual in- depth interviews. There was a consensus that the programme should if possible, begin with a pilot scheme but ran by private entrepreneurship without government involvement, since it was felt to be the responsibility of the family, both nuclear and extended, to look after their own. It would also be the responsibility of these entrepreneurship to create awareness of the programme and execute it. With no explicit planning for ageing in either the formal or informal sectors there is a high likelihood that people will end up in poverty, especially in the case of women who depend on their spouses. Government program must also be made known to everyone, especially the aged, so that they know what their statutory entitlements are.

\author{
List of abbreviations \\ Afakye - Festival \\ AM - Assembly Member \\ CCMA - Cape Coast Metropolitan Area \\ EBAN - Elderly Welfare Card \\ LEAP - Livelihood Empowerment Against Poverty Programme \\ MD - Medical Director \\ NHIS - National Health Insurance Scheme \\ RSW - Regional Social Worker \\ SHI - Social Health Insurance \\ WHO - World Health Organization
}

\section{Ethical approval}

This study was approved by the humanities and Social Sciences Research Ethics Committee of the University of KwaZulu-Natal (HSS/0608/016D) and the Dodowa Health Research Centre (Ghana Health Service) (DHRC/06/06/16). Voluntary participation was accorded with written and signed consent.

\section{Limitations of the study}

Purposive sampling procedures, followed with adjustments when getting stakeholders was difficult. Researcher impact on the study participants was low but the sample size limits the possibility of generalizing the findings beyond the geographical area studied.

\section{Competing interests}

The authors declare that they have no competing interests

\section{Authors' contributions}

1A conceived the study, was the principal investigator (PI) and made a substantial contribution to the research as well as drafting the manuscript. BPN was involved in the conception of the research, guided the development of the manuscript to its logical completion and contributed to the draft of the manuscript. Both $1 \mathrm{~A}$ and BPN revised the manuscript for its intellectual content then approved the final version to be submitted for publication. 


\section{Author information}

1A is a nurse educator and a lecturer at the University of Cape Coast, Department of Health Sciences, Cape Coast, Ghana. BPN is a Professor of Nursing and Divisional Vice Chancellor of the College of Health at the University of KwaZulu-Natal in Durban, South Africa.

\section{Acknowledgements}

We thank the stakeholders that granted audience to conduct this research, and the field work was supported by bursary from the College of Health Sciences, University of KwaZulu-Natal, Durban, South Africa.

\section{References}

[1] WHO (2017) Ageing and life-course, http://who.int/ageing/age-friendly-world/en/conference paper accessed 28 June 2017

[2] Chamie J, (2012). For Better Planning, Watch Global Demographic Trends, YaleGlobal, YaleGlobal Online, A publication of the MacMillan Center. Accessed on the $28^{\text {th }}$ June 2017

[3] Kaneda, T., (2016). A Critical Window for Policymaking on Population Aging in Developing Countries, Population Reference Bureau, 1875 Connecticut Avenue, NW Suite 520, Washington, DC 20009

[4] United Nations (2015). Population ageing and sustainable development, Population facts, United Nations, department of Economics and Social Affairs, Population division. October 2015 No. 2014/4/Rev.1

[5] Zaidi. A, (2015). Ageing and Development, United Nations Development Programme, Human Development Reports, HelpAge International's 2015 Global AgeWatch Index's Insight report, pp. 5.

[6] The Economist (2014). Age invaders Demography, growth and inequality, UN population division, online publication, accessed through google engine search 29 June, 2017

[7] Bloom, D. E., Canning D., \& Fink, G. (2010). Implications of population ageing for economic growth Oxford Review of Economic Policy, Volume 26, Number 4, 2010, pp. 583-612

[8] Tostensen, A. (2008). Feasible social security systems in Africa, DevISSues Development ISSues Volume10/Number2/November 2008.

[9] Van der Geest S. 2002. Respect and reciprocity: Care of elderly people in rural Ghana, Journal of Cross-Cultural Gerontology 17: 3-31.

[10] WHO (2001) Health and Ageing: A Discussion Paper, World Health Organization, Department of Health Promotion, Non-Communicable Disease Prevention and Surveillance 20 Avenue Appia, CH 1211 Geneva 27, Switzerland activeageing@,who.int

[11] Carrin. G., Doetinchem, O., Kirigia, J., Mathauer, I. and Musango L. (2008). Social health insurance: how feasible is its expansion in the African Region? DevISSues Development ISSues Volume10/Number2/November 2008.

[12] U S Department of Health and Human Services. 2003. The Affordable Care Act was signed into law, putting in place comprehensive U.S. health insurance reforms, https://www.hhs.gov/about/historical-highlights/index.html. Accessed 19 march 2020

[13] Kim, K. \& Antonopoulos, R. (2011), Unpaid and Paid Care: The Effects of Child Care and Elder Care on the Standard of Living. Levy Economics Institute Working Paper No. 671. Available at SSRN: https://ssrn.com/abstract=1846741 or http://dx.doi.org/10.2139/ssrn.1846741

[14] Congressional Budget Office CBO (2004). Incorporating Longevity Effects into Long-Term Medicare Projections: Technical Paper 2004-02: Working Paper, Congressional Budget office; https://www.cbo.gov/sites/default/files/108thcongress-2003-2004/working paper/2004-2_0.pdf

[15] Medicare Payment Advisory Commission (MEdpAC) (2018) A Data Book: Health care spending and the Medicare program, 142-55, http://www.medpac.gov/docs/defaultsource/databook/jun18_databookentirereport_sec.pdf. Access on March 2020 
Aboh, I. K. \& Ncama, B. P. (2020). Perceptions of Government Stakeholders On Ageing And Assisted Care In The Cape Coast Municipal Area. Advances_in Social Sciences Research Journal, 7(4) 71-86.

[16] National Institute of Ageing (2017), long term care, US Department of Health and Human Services. https://www.nia.nih.gov/health/residential-facilities-assisted-living- and nursing-homes. Accessed 13th March 2020

[17] Mollica, R. L. 2000. State Assisted Living Policy. Portland, ME: National Academy for State Health Policy. Accessed August 7th 2017

[18] Genworth (2014) Cost of Care Survey; Executive Summary, 2014 Genworth Financial, Inc. online publication, accessed August 7th 2017

[19]SeniorAdvisor.com (2017) https://www.senioradvisor.com/ind/assisted-living\#VC77Ti4AADMAOtWB accessed August 7th 2017.

[20] Frytak, J.R., Kane, R. A., Finch, M. D., Kane, R. L. and Maude-Griffin, R. (2001), Outcome trajectories for assisted living and nursing facility residents in Oregon. Health Serv Res. 36(1 Pt 1): 91-111

[21] Lee, W. K. M., (2003) Women and Retirement Planning: Towards the "Feminization of Poverty" in an Aging Hong Kong, Journal of Women \& Aging, 15:1, 31-53, DOI:10.1300/J074v15n01_04

[22] Noone, J., Stephens,C. and Alpass, F. M.( 2010), Do Men and Women Differ in Their Retirement Planning? Testing a Theoretical Model of Gendered Pathways to Retirement Preparation, Research on Aging 32(6):715-38, DOI: $10.1177 / 0164027510383531$

[23] Helman, R., Greenwald. M., \& Van Derhei. J. (2007). The Retirement System in Transition: The 2007 Retirement Confidence Survey, EBRI Issue Brief No. 304: 1-29

[24] Ng, T., Tay, W., Tan, N. and Lim, Y., (2011), Influence of Investment Experience and Demographic Factors on Retirement Planning Intention, International Journal of Business and Management, Vol. 6, No. 2; 196-204

[25] Li, R. M., Iadarola, A. C. and Maisano, C. C., (2007). Why population ageing matters: A Global Perspective, National Institute on ageing National Institutes of Health U.S. Department of Health and Human Services, U.S. Department of State

[26] Dosu (2014), Elderly Care in Ghana, HKAG publications. 